\title{
PATOFISIOLOGIA DA DOR
}

\section{(Pathophysiology of pain)}

\author{
KLAUMANN, P. R. ${ }^{1}$; WOUK, A. F. P. F. ${ }^{2}$; SILLAS, T. ${ }^{1}$ \\ ${ }^{1}$ Curso de Pós-graduação em Ciências Veterinárias - UFPR \\ ${ }^{2}$ Departamento de Medicina Veterinária - UFPR
}

\begin{abstract}
RESUMO - A dor pode ser definida como uma experiência sensorial e emocional desagradável, associada a uma lesão real ou potencial. A dor fisiológica é um reflexo protetor do organismo, para evitar uma injúria ou dano tecidual. Frente à lesão tecidual a dor patológica providenciará condições para a cicatrização. Uma vez instalada a injúria pode se introduzir o conceito de dor patológica que, segundo sua origem, pode ser classificada como nociceptiva (somática ou visceral) ou neuropática. A dor pode também ser classificada segundo determinação temporal em dor aguda ou crônica. A nocicepção é o componente fisiológico da dor e compreende os processos de transdução, transmissão e modulação do estímulo nociceptivo. Uma vez instalado o estímulo nociceptivo, diversas alterações neuroendócrinas acontecem, promovendo um estado de hiperexcitabilidade do sistema nervoso central e periférico. O objetivo da presente revisão é abordar a fisiopatologia do processo doloroso, bem como suas aplicações na terapêutica analgésica.
\end{abstract}

Palavras-Chaves: dor, patofisiologia, anagesia, cão.

ABSTRACT - Pain can be defined as an uncomfortable sensorial and emotional experience, associated with real or potential tissue damage. Physiologic pain is a protective reflex that prevents tissue damage. If injury or tissue damage occurs, pathologic pain is recognized to provide healing conditions. Based in the origin of pathologic pain, a classification of nociceptive, including somatic and visceral pain, and neuropathic pain is recognized. Pain could also be classified as acute or chronic. Nociception is the phisiologic component of pain and includes de concepts of trasnduction, transmission and modulation of nociceptive stimuli. If nociceptive stimuli is determined, several neuroendocrine responses occur, and a hiperexcitability state of the periferic and central nervous system is already installed. This article reviews the pathophysiologic pathways and their applications to pain treatment. Key words: pain, pathophysiology, dog, analgesia.

\section{INTRODUÇÃO}

A dor foi conceituada pela primeira vez em 1986, pela Associação Internacional para o Estudo da Dor, como uma experiência sensorial e emocional desagradável que está associada a lesões reais ou potenciais. O termo nocicepção está relacionado com o reconhecimento de sinais dolorosos pelo sistema nervoso, que formulam informações relacionadas à lesão. Baseado nestes conceitos, o termo dor seria melhor aplicado a seres humanos do que aos animais, pelo fato deste termo envolver um componente emocional. Mesmo assim tornou-se uma convenção o uso do termo "dor" para pacientes humanos e animais (HELLEBREKERS, 2002). LUNA (2006) considera a dor como sendo o quinto sinal vital, juntamente com a função cardiorespiratória e a térmica.

A exposição da pele ou qualquer outro órgão a estímulos potencialmente nocivos induz à sensação desagradável, informando o indivíduo sobre o perigo real ou potencial para sua integridade física. Portanto, a informação processada pode ser diferenciada como dor fisiológica ou dor patológica (FANTONI e MASTROCINQUE, 2002; ALMEIDA et al., 2006).

A dor fisiológica é aquela que induz respostas protetoras, como o reflexo de retirada (ou reação de fuga), com intuito de interromper a exposição ao estímulo nocivo. Este sinal é típico da dor aguda produzida por estímulos intensos na superfície da pele. A dor visceral e a dor somática profunda são causadas por estímulos inevitáveis e apresentam respostas adaptativas específicas, geralmente são subagudas e podem vir acompanhadas de respostas autonômicas ou comportamentais específicas (FANTONI e MASTROCINQUE, 2002; HELLEBREKERS, 2002).

Embora a inatividade temporária e o comportamento protetor como resposta à dor subaguda possam trazer benefícios, a dor persistente pode levar a um estado de depressão semelhante ao desencadeado por estímulos estressantes inevitáveis, não podendo ser considerada como uma resposta adaptativa. Estados dolorosos prolongados estimulam 
persistentemente os aferentes nociceptivos induzindo alterações que aumentam os efeitos deletérios da dor crônica, introduzindo então o conceito de dor patológica. Enquanto a dor aguda é um sintoma de alguma doença, a dor crônica é uma doença propriamente dita, sendo nociva e independente ao estímulo que a gerou (FANTONI e MASTROCINQUE, 2002; HELLEBREKERS, 2002).

A dor persistente pode ser subdividida segundo sua origem em nociceptiva e neuropática. A dor nociceptiva resulta da ativação direta de nociceptores da pele e outros tecidos em resposta a uma lesão tecidual, acompanhada de inflamação. A dor neuropática ou neurogênica origina-se devido a lesões de nervos periféricos ou do sistema nervoso central (FANTONI e MASTROCINQUE, 2002; ALMEIDA et al., 2006).

É importante a descrição de algumas definições correlacionadas à dor e suas formas de percepção:

- Nociceptor: receptor periférico que responde a estímulos nocivos.

- Limiar à dor: a menor intensidade de estímulo que permite ao indivíduo perceber a dor.

- Alodinia: dor que surge como resultado de estimulação não-nociva sobre a pele normal.

- Hiperalgesia: aumento da resposta dolorosa produzida por um estímulo nocivo.

- Hiperalgesia primária: hiperalgesia na região da lesão tecidual.

- Hiperalgesia secundária: hiperalgesia na região que circunda a lesão tecidual.

- Analgesia: redução ou anulação da dor.

- Hiperestesia: sensibilidade aumentada à estimulação.

- Neuralgia ou nevralgia: dor localizada eu uma região inervada por nervo específico ou grupo de nervos (MUIR III et al., 2001; FANTONI e MASTROCINQUE, 2002).

\section{Dor Fisiológica - Nocicepção}

O componente fisiológico da dor é chamado nocicepção, que consiste dos processos de transdução, transmissão e modulação de sinais neurais gerados em resposta a um estímulo nocivo externo. De forma simplificada, pode ser considerado como uma cadeia de três-neurônios, com o neurônio de primeira ordem originado na periferia e projetando-se para a medula espinhal, o neurônio de segunda ordem ascende pela medula espinhal e o neurônio de terceira ordem projeta-se para o córtex cerebral (MESSLINGER, 1997; TRANQUILLI, 2004).
Os dois sistemas de modulação nociceptiva mais importantes são mediados por receptores NMDA (N-Metil-D-Aspartato) e opióides, distribuídos por toda extensão do sistema nervoso central. Entre os três principais subtipos de receptores opióides, os receptores $\mu$ e $\delta$ podem inibir ou potencializar eventos mediados pelos receptores NMDA, enquanto o receptor $\kappa$ antagoniza a atividade mediada por receptores NMDA. (RIEDEL e NEECK, 2001).

Segundo PISERA (2005) o primeiro processo da nocicepção é a decodificação de sensações mecânica, térmica e química em impulsos elétricos por terminais nervosos especializados denominados nociceptores. Os nociceptores são terminações nervosas livres dos neurônios de primeira ordem, cuja função é preservar a homeostasia tecidual, assinalando uma injúria potencial ou real. Os neurônios de primeira ordem são classificados em três grandes grupos, segundo seu diâmetro, seu grau de mielinização e sua velocidade de condução:

1. Fibras $A \beta$ : são fibras de diâmetro grande (maior que $10 \mu \mathrm{m}$ ), mielinizadas e de condução rápida, responsáveis por sensações inócuas (FIGURA 1).

2. Fibras $A \delta$ : são de diâmetro intermediário (2 a 6 $\mu \mathrm{m})$, mielinizadas. Sua velocidade de condução é intermediária, modulando a primeira fase da dor: mais aguda ou semelhante à pontada.

3. Fibras C: são fibras de diâmetro pequeno $(0,4$ a 1,2 $\mu \mathrm{m}$ ), não mielinizadas e de velocidade de condução lenta, responsáveis pela segunda dor ou dor difusa, queimação persistente.

4. Na ausência de dano tecidual ou nervoso as fibras $A \beta$ somente transmitem informação referente a estímulos inócuos, como tato, vibração e pressão. Normalmente, a informação nociceptiva é transmitida por fibras do tipo $\mathrm{C} \mathrm{e}$ A $\delta$ localizadas na pele, vísceras, vasos sanguíneos, peritôneo, pleura, periósteo, tendão, fáscia, cápsula articular e fibras do músculo esquelético; sua distribuição dependendo da espécie e localização anatômica, podendo aparecer a cada 2 a $10 \mathrm{~mm}$ (MESSLINGER, 1997; LAMONT e TRANQUILLI, 2000; MUIR III et al., 2001). As fibras $A \delta$ são responsáveis pela primeira fase da dor, rápida e forte, do tipo picada ou ferroada e são sensíveis a estímulos mecânicos intensos (mecanorreceptores de alto limiar). As fibras $\mathrm{C}$ produzem uma segunda fase 
de dor mais difusa e persistente e formam, na periferia, receptores de alto limiar para estímulos térmicos e/ou mecânicos. Existem também fibras do tipo $\mathrm{C}$ polimodais que respondem a estímulos mecânicos, térmicos e químicos. Os campos receptivos destes neurônios oscilam entre 2 e 10 mm (BESSON, 1997; TRANQUILLI, 2004; PISERA, 2005).

FORSS N. et al. (2005) relatam que os impulsos nociceptivos mediados pelas fibras $A \delta$ e $C$ são processados numa mesma área no córtex cerebral porém em diferentes janelas de tempo.
As fibras aferentes nociceptivas terminam no corno dorsal da medula, que pode ser dividida em seis lâminas. Os neurônios nociceptivos do corno dorsal estão localizados nas lâminas mais superficiais: a lâmina marginal (lâmina I) e a substância gelatinosa (lâmina II). A maioria desses neurônios recebem conexões diretas de fibras Aঠ e C. Muitos dos neurônios da lâmina I respondem exclusivamente a estímulos nociceptivos e projetam-se para centros superiores. Alguns neurônios dessa lâmina, denominados neurônios de faixa dinâmica ampla (WDR), respondem de maneira gradativa a estimulação mecânica nociva e inócua. A substância gelatinosa (lâmina ll)é formada quase que exclusivamente por interneurônios, tanto inibitórios quanto excitatórios (TRANQUILLI, 2004; PISERA, 2005; DREWES, 2006).

FIGURA 1 - FIBRAS AFERENTES RESPONSÁVEIS PELAS INFORMAÇÕES NOCICEPTIVAS.

\section{Estímulo de baixa intensidade}

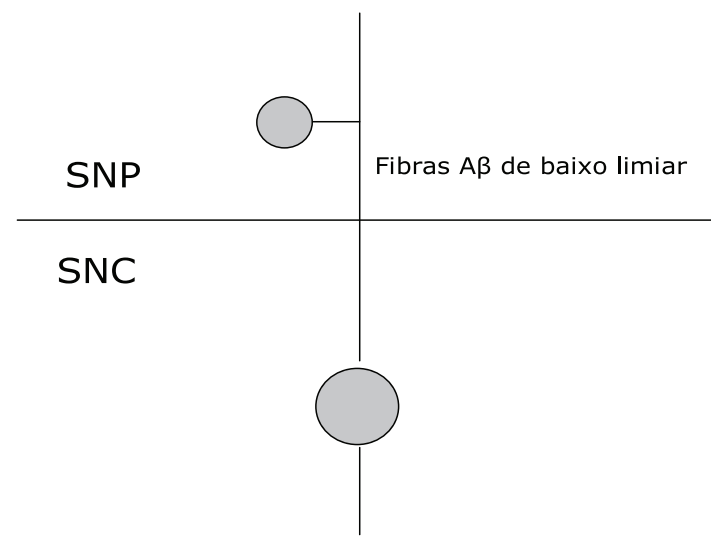

Sensação Inócua

As lâminas III e IV possuem neurônios que se conectam diretamente com terminais centrais de fibras $A \beta$, que respondem predominantemente a estímulos inócuos. A lâmina $V$ possui neurônios WDR que se projetam ao tronco encefálico e certas regiões do tálamo. Recebem contatos monossinápticos de fibras $A \delta$ e $A \beta$, também recebem informações de fibras C. Os neurônios da lâmina VI estão conectados de forma monossináptica com aferentes $A B$ de músculos e articulações e respondem a estímulos inócuos. Finalmente os neurônios das lâminas VII e VIII do corno ventral podem responder a estímulos nociceptivos, mesmo que de forma mais complexa, através de conexões polissinápticas (PISERA, 2005).

Segundo KITAGAWA et al. (2005) os neurônios nociceptivos em indivíduos idosos exibem hiperexcitabilidade, sugerindo que o sistema nociceptivo do corno dorsal da medula espinhal torna-se sensibili-

\section{Estímulo de alta intensidade}

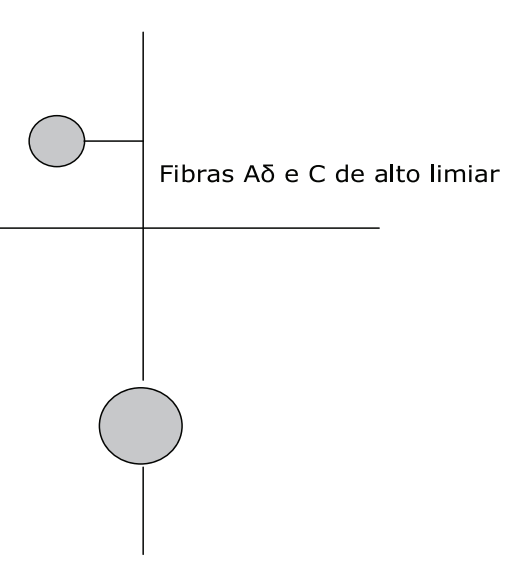

Dor

zado com o avanço da idade. Sua excitabilidade não pode ser aumentada pelo processo inflamatório.

As fibras aferentes (FIGURA 2) de primeira ordem formam conexões diretas ou indiretas com uma das três populações de neurônios do corno dorsal da medula: 1) interneurônios, subdivididos em excitatórios e inibitórios; 2 ) neurônios proprioespinhais que extendem-se por múltiplos segmentos espinhais e estão envolvidos com a atividade reflexa; 3) neurônios de projeção (WDR) que participam na transmissão rostral através da medula espinhal até centros supraespinhais como o mesencéfalo e córtex. Os três componentes são interativos e são essenciais para o processamento da informação nociceptiva, o que facilita a geração de uma resposta à dor apropriada e organizada (MILLAN, 1999; LAMONT e TRANQUILLI, 2000; DREWES, 2006). 


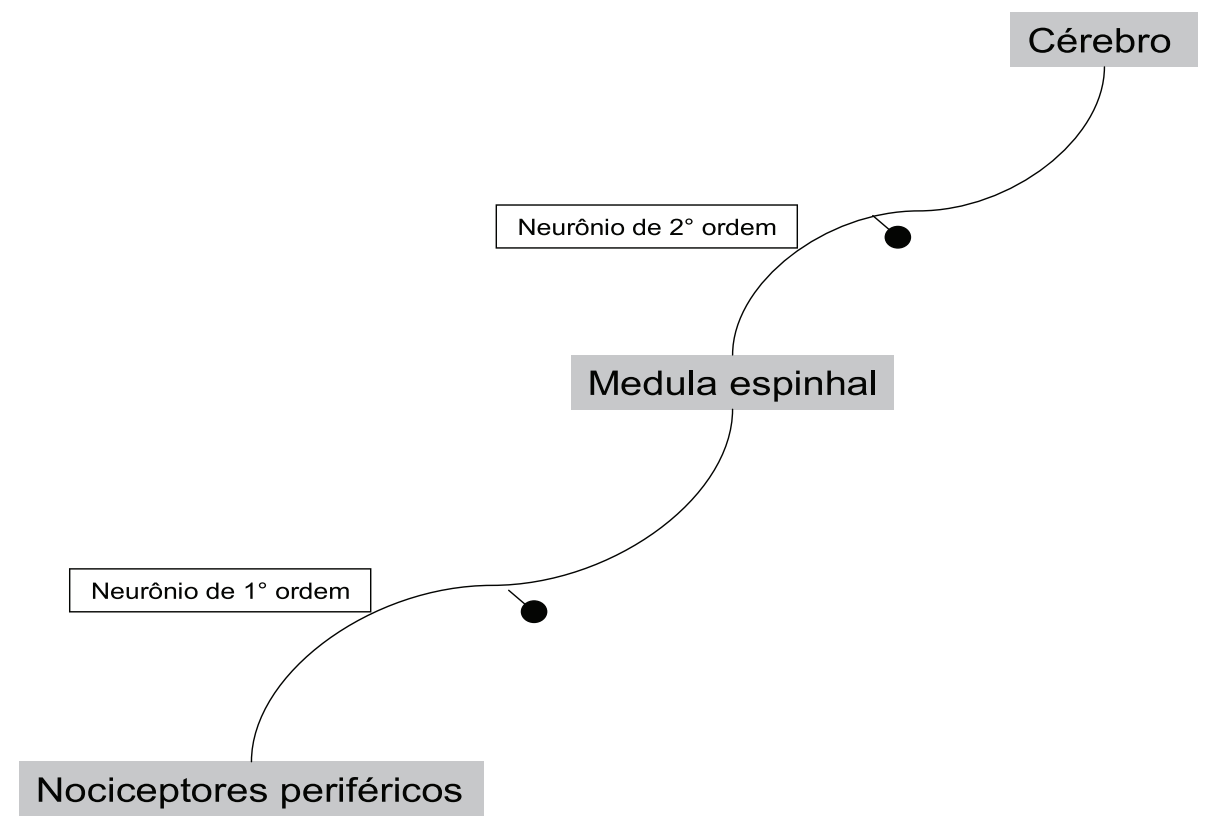

Particular atenção é dada aos interneurônios opioidérgicos, que expressam encefalinas e dinorfina. Esses peptídeos inibem pré-sinapticamente a liberação de glutamato, substância $\mathrm{P}$ e o peptídeo relacionado com o gene da calcitonina, a partir de aferentes nociceptivos primários interagindo com receptores $\mu$ (OP3), $\delta$ (OP2) e $\kappa(\mathrm{OP} 1)$ (PISERA, 2005; DREWES, 2006).

A comunicação da informação nociceptiva entre neurônios ocorre por mediadores químicos (neurotransmissores) que são: aminoácidos excitatórios ou inibitórios e neuropetídeos que são produzidos, armazenados e liberados tanto nas terminações dos nervos aferentes como nos neurônios do corno dorsal. Os principais aminoácidos excitatórios são o glutamato e o aspartato porém, em fibras aferentes do tipo $C$ também encontra-se uma variedade de neuropeptídeos como a substância $P$, neurotensina, peptídeo intestinal vasoativo, peptídeo relacionado com o gene da calcitonina e colecistocinina (LAMONT e TRANQUILLI, 2000; RYGH et al., 2005).

FIGURA 3 - ESQUEMA DE SENSIBILIZAÇÃO DE NEURÔNIOS PERIFÉRICOS, APÓS INJÚRIA TECIDUAL.

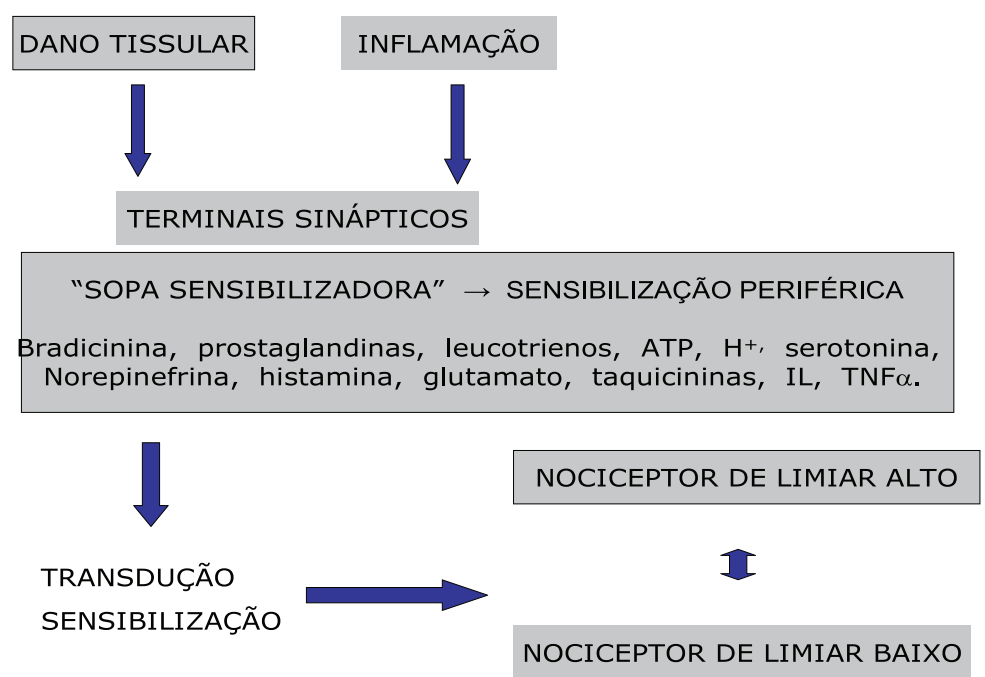


Em comparação com as fibras aferentes primárias e a medula espinhal, pouco se sabe no que diz respeito a neurotransmissores e receptores envolvidos em neurônios nociceptivos ou em vias modulatórias para estes neurônios a nível talâmico e cortical. Acredita-se que o glutamato e o aspartato constituam o principal mediador excitatório envolvido na transmissão e processamento no sistema talamocortical. Os aminoácidos inibitórios (GABA e glicina), as monoaminas (norepinefrina, serotonina e dopamina), acetilcolina e histamina também estão relacionadas com a excitabilidade talamocortical (LAMONT e TRANQUILLI, 2000). É interessante destacar que o córtex cerebral expressa COX-2, o que sugere um provável papel das prostaglandinas na modulação da informação nociceptiva nesta estrutura. Também foi demonstrada a expressão de citocinas no córtex cerebral (PISERA, 2005; RYGH et al., 2005).

A informação sobre o dano tecidual é conduzida por neurônios de projeção através de cinco vias ascendentes principais (FIGURA 3):

1. Trato espinotalâmico. Composto por neurônios nociceptivos específicos e axônios de neurônios WDR das lâminas I e V - VII da medula espinhal. Esses neurônios projetam-se no sentido contralateral até o tálamo.

2. Trato espinorreticular. Compreende axônios de neurônios das lâminas VII e VIII que terminam na formação reticular (bulbar e pontina), para logo ascender até o tálamo. Muitos dos axônios do trato espinorreticular ascendem sem cruzar a linha média.

3. Trato espinomesencefálico. É formado por axônios de neurônios de projeção das lâminas I e IV que se projetam contralateralmente até a formação reticular mesencefálica e a substância cinzenta periaquedutal até os núcleos parabraquiais da formação reticular. Os neurônios parabraquiais projetam-se até a amigdala, um dos principais componentes do sistema límbico, o que sugere que o trato espinomesencefálico contribui com os componentes afetivos da dor.

4. Trato espinocervical. Origina-se principalmente nas Lâminas III e IV. Sua fibras fazem uma conexão sináptica no núcleo cervical lateral e no primeiro e segundo segmentos cervicais, para logo chegar ao tálamo através do trato cervicotalâmico.
5. Trato espinohipotalâmico. Compreende axônios provenientes das lâminas I, V e VIII, que projetam-se diretamente no hipotálamo. Essas conexões participam nas respostas neuroendócrinas e autonômicas induzidas pela dor (LAMONT e TRANQUILLI, 2000; PISERA, 2005).

Este complexo sistema de vias diretas e indiretas de transmissão das informações nociceptivas inervam o tálamo, o mesencéfalo, o sistema límbico e a formação reticular. Estes centros nervosos são responsáveis pela localização da dor, sua intensidade, bem como os aspectos afetivos e cognitivos (PISERA, 2005).

PLONER et al. (2006) observaram que a velocidade de condução da informação dolorosa tanto na periferia quanto na medula espinhal é mais lenta que a transmissão da informação tátil. Entretanto o processamento cerebral da dor é substancialmente mais rápido do que o processamento da informação tátil, compensando a condução lenta da periferia e da medula espinhal. A conseqüência é um curto período de latência estímulo-resposta, gerando resposta comportamental protetora imediata.

A região anatômica mais importante para o sistema de analgesia endógeno é a substância cinzenta periaquedutal do mesencéfalo, considerada por alguns com sendo uma extensão caudal do sistema límbico dentro do mesencéfalo (LAMONT e TRANQUILLI, 2000). Este bloqueio é produzido pela estimulação de vias descendentes que inibem os neurônios nociceptivos na medula espinhal, através de conexões excitatórias com neurônios serotoninérgicos e neurônios noradrenérgicos, que por sua vez descem até o corno dorsal da medula onde realizam conexões inibitórias com neurônios das lâminas I, II e V (PISERA, 2005).

Essas projeções descendentes originadas no tronco encefálico podem inibir a descarga de neurônios nociceptivos de projeção, atuando diretamente sobre eles, por inibição de interneurônios excitatórios ou por estimulação de interneurônios inibitórios. Além disso, estabelecem sinapse com terminais de aferentes primários reduzindo a liberação de glutamato, aspartato e peptídeo relacionado com o gene da calcitonina. Além de sua ação medular, os peptídeos opióides participam da ativação dos sistemas de inibição descendentes. A substância cinzenta periaquedutal contém uma grande quantidade de receptores $\mu(\mathrm{OP} 3)$. Os peptídeos opióides inibem a descarga dos neurônios GABAérgicos inibitórios, ativando as vias descendentes. (PISERA, 2005; DREWES, 2006). 


\section{Dor patológica}

A dor fisiológica descrita até aqui, como uma entidade isolada é um evento raro. Na maioria das vezes o estímulo nocivo não é transitório e pode estar associado com inflamação e injúria nervosa significativa. Sob tais circunstâncias, alterações dinâmicas no processamento da informação nociva são evidentes nos sistemas nervoso periférico e central. Este tipo de dor é chamado dor patológica e envolve desconforto e sensibilidade anormal na sintomatologia clínica do paciente. A dor patológica pode surgir de diferentes tecidos e pode ser classificada com dor inflamatória (envolvendo estruturas somáticas ou viscerais) ou neuropática (envolvendo lesões do sistema nervoso). É importante a caracterização temporal da dor, fazendo distinção entre dor aguda (ocorrência recente) ou dor crônica (longa duração) (LAMONT e TRANQUILLI, 2000; Jl e WOOLF, 2001; SCHAIBLE, 2006).

A dor aguda tipicamente surge do trauma de tecidos moles ou inflamação e está relacionada com um processo adaptativo biológico para facilitar o reparo tecidual e cicatricial. A hipersensibilidade na área da injúria (hiperalgesia primária), bem como nos tecidos adjacentes (hiperalgesia secundária) contribuem para que o processo cicatricial ocorra sem interferências (LAMONT e TRANQUILLI, 2000; JI e WOOLF, 2001; MUIR III et al., 2001).

A dor crônica persiste além do período esperado de uma doença ou injúria e tem sido arbitrariamente definida como aquela com duração maior que 3 a 6 meses. Pode manifestar-se espontaneamente ou ser provocada por vários estímulos externos. A resposta é tipicamente exagerada em duração, amplitude, ou ambas. A dor crônica além de simplesmente manifestar-se por um longo período de tempo, implica numa síndrome debilitante que possui um significante impacto sobre a qualidade de vida do paciente e caracteriza-se por uma resposta pobre às terapias analgésicas convencionais (LAMONT e TRANQUILLI, 2000; JI e WOOLF, 2001).

O sistema nociceptivo é capaz de sofrer alterações nos mecanismos de percepção e condução dos impulsos, denominados neuroplasticidade. A neuroplasticidade pode aumentar a magnitude da percepção da dor e pode contribuir para o desenvolvimento de síndromes dolorosas crônicas (PETERSEN-FELIX e CURATOLO, 2002).

\section{Dor inflamatória ou nociceptiva}

A hipersensibilidade é a principal característica da dor patológica e resulta de alterações drásticas na função do sistema nervoso. Este conjunto de alterações denominadas plasticidade do sistema nervoso, é um fenômeno que acontece perifericamente por redução do limiar de ativação dos nociceptores; bem como centralmente, pela responsividade aumentada da medula espinhal aos estímulos sensoriais. (LAMONT e TRANQUILLI, 2000; SCHAIBLE 2006).

Sob circunstâncias fisiológicas normais, estímulos mecânicos, térmicos e químicos ativam nociceptores associados com fibras $A \delta$ e $C$ para avisar sobre um estímulo nocivo. Cada estímulo está associado com certo grau de inflamação que inicia uma cascata de sensibilização periférica com eventos celulares e subcelulares. Células lesadas e fibras aferentes primárias liberam uma série de mediadores químicos, incluindo substância $P$, neurocinina Ae peptídeo relacionado com o gene da calcitonina, que têm efeitos diretos sobre a excitabilidade de fibras sensoriais e simpáticas. Estes mediadores também promovem vasodilatação com extravasamento de proteínas plasmáticas e o recrutamento de células inflamatórias. Mastócitos, macrófagos, linfócitos e plaquetas contribuem para a formação de um ambiente complexo, composto por mediadores inflamatórios, como íons hidrogênio, norepinefrina, bradicinina, histamina, íons potássio, citocinas, serotonina, fator de crescimento neural, óxido nítrico e produtos das vias da ciclo-oxigenase e lipo-oxigenase do metabolismo do ácido araquidônico. Parece que estas moléculas agem melhor sinergicamente do que isoladamente, gerando o que se chama "sopa sensibilizadora" que efetivamente desencadeia a resposta para ativação das fibras $A \delta$ e $C$. Enquanto alterações no limiar de transdução aferente caracterizada pela sensibilização periférica são responsáveis pela zona de hiperalgesia primária na região da injúria tecidual, elas não explicam os aspectos comportamentais da dor, clinicamente. Entretanto, a identificação de uma subpopulação de terminais nervosos aferentes chamados nociceptores silenciosos tem contribuído para entendermos o fenômeno de sensibilização periférica. Estes nociceptores pertencem a uma classe de fibras $\mathrm{C}$ polimodais, amielínicas que demonstram pequena ou nenhuma atividade até que seja submetida à estimulação extrema; entretanto, eles são excessivamente sensibilizados pelos efeitos da inflamação local e podem disparar vigorosamente sob tais condições (GARRY et al., 2004; LAMONT e TRANQUILLI, 2000; MUIR III et. al., 2001; SCHAIBLE 2006; SCHAIBLE 2007).

Associada à hiperalgesia primária (no local da injúria) e secundária (nos tecidos ao redor da injúria), observa-se também alodinia (sensibilidade a estímulos inócuos). Tal condição é agora reconhecida como resultado de alterações dinâmicas na excitabilidade dos neurônios do corno dorsal (sensibilização central), que modifica suas propriedades nos campos receptivos. O primeiro estágio está relacionado à 
duração dos potenciais de ação sinápticos lentos gerados por fibras A $\delta$ e $\mathrm{C}$. Os potenciais sinápticos podem durar mais de 20 segundos e resulta na soma de potenciais de baixa freqüência repetidos em nociceptores estimulados, gerando uma despolarização progressiva e de longa duração (LTP - long term potentioation) nos neurônios do corno dorsal. Somente alguns segundos de estímulo de fibras $C$ podem gerar vários minutos de despolarização pós-sináptica. Também observa-se um tipo de potenciação a curto prazo em neurônios espinhais após estimulação de fibras C. Este evento, chamado "Wind-up", é mediado por receptores NMDA (N-metil-D-aspartato), que ligam-se ao glutamato; e receptores da taquicinina, que ligam-se à substância $P$ e à neurocinina $A$. $A$ ativação de receptores NMDA resulta em influxo de cálcio e ativação da proteína cinase $C$, que modifica estruturalmente o canal de NMDA, aumentando sua sensibilidade ao glutamato (LAMONT e TANQUILLI, 2000; GARRY et al., 2004; SCHAIBLE 2006).

As fibras $A \beta$ que antes respondiam apenas à sensações inócuas, são agora recrutadas gerando dor como resultado do processamento central alterado no corno dorsal da medula espinhal (LAMONT e TANQUILLI, 2000; GARRY et al., 2004; SCHAIBLE 2006).

Os neurônios aferentes sofrem também alterações fenotípicas importantes, em conseqüência da exposição a neurotrofinas como o fator de crescimento neural (NGF), liberado por células de Schwann, macrófagos, fibroblastos e queratinócitos, aumentando a expressão de substância P, glutamato, óxido nítrico e peptídeo relacionado ao gene da calcitonina (PISERA, 2005).

\section{Dor visceral}

Os mecanismos neurais que envolvem a geração da dor inflamatória e da dor visceral, por muito tempo foram tidos como iguais, porém existem diferenças relevantes. As vísceras raramente são expostas a estímulos externos mas são alvos comuns de diversas doenças. $\mathrm{O}$ conceito de aferentes nociceptivos ativados por um estímulo direto sobre o tecido é difícil de transferir para os tipos de dor visceral. A sensibilidade do tecido visceral a estímulos térmicos, químicos e mecânicos difere significativamente. As vísceras parecem mais sensíveis à distensão de órgãos cavitários de parede muscular, sem dano tecidual, isquemia, e inflamação. Aárea sobre a qual o estímulo acontece pode ser uma determinante crucial no desenvolvimento dos tipos de dor. Os receptores mecânicos ou mecanorreceptores existentes na musculatura lisa de todas as vísceras ocas são do tipo $A \delta$ e $\mathrm{C}$, e respondem a estímulos mecânicos leves, tensão aplicada ao peritônio, contração e distensão da musculatura lisa. $O$ trato gastrintestinal possui receptores químicos e mecânicos de adaptação lenta e rápida que são classificados em dois grupos: o grupo de receptores de alto limiar para estímulos mecânicos leves, e o grupo de baixo limiar para estímulos mecânicos que responde a estímulos agressivos e não agressivos. O primeiro grupo é encontrado no esôfago, sistema biliar, intestino delgado e cólon e o segundo, apenas, no esôfago e cólon. A relação entre a intensidade do estímulo e a atividade nervosa é somente evocada após a estimulação nociva. (LAMONT e TRANQUILLI, 2000; KRAYCHETE e GUIMARÃES, 2003). A dor visceral é profunda e dolorosa, mal localizada e, freqüentemente relacionada a um ponto cutâneo. O mecanismo da dor referida não está totalmente esclarecido, mas pode ser relacionado a ponto de convergência de impulso sensorial cutâneo e visceral em células do trato espinotalâmico na medula espinhal. (GOMES et al., 2002)

\section{Dor neuropática}

A dor neuropática ou neurogênica é produzida pelo dano ao tecido nervoso. Caracteriza-se pela aparição de hiperalgesia, dor espontânea, parestesia e alodinia mecânica e por frio (PISERA, 2005; SCHAIBLE, 2006).

A lesão de nervos periféricos induz descargas rápidas e intensas por períodos mais ou menos prolongados, na ausência de estímulos. Estes estímulos parecem produzir a ativação de receptores NMDA, originando o fenômeno de "wind up" nos neurônios do corno dorsal da medula. Logo depois a indução de processos inflamatórios faz com que certos mecanismos desencadeantes da dor neurogênica sejam comuns ao da dor nociceptiva. As extremidades do nervo lesionado "aderem-se" logo após o trauma, podendo formar uma estrutura de crescimento irregular denominada neuroma, que pode dar origem a descargas espontâneas e hipersensibilidade a estímulos mecânicos. São produzidos padrões anormais de comunicação interneuronal na periferia, nas quais um neurônio modifica a atividade de neurônios adjacentes. Logo após a lesão, as fibras simpáticas (que normalmente não afetam a sinalização dos terminais sensoriais) respondem a estímulos, tanto na periferia como nos gânglios da raiz dorsal, a agonistas $\alpha$ (norepinefrina), em particular os neurônios $A \beta$. Os neurônios aferentes lesados também sofrem alterações fenotípicas, observando-se maior expressão de peptídeos pró-nociceptivos, como a colecistoquinina (TJOLSEN e HOLE, 1993; LAMONT e TRANQUILLI, 2000; JI e STRICHARTZ, 2004; SCHAIBLE, 2006). 
Segundo PITCHER e HENRY (2005) em consequência das alterações fenotípicas que acontecem durante a neuropatia periférica, os aferentes mielinizados sintetizam e liberam substância $P$ que ligamse a receptors NK-1. O resultado é a expressão de neurônios nocicpetivos espinhais que respondem de forma exagerada a estímulos inócuos.

Uma importante seqüela da injúria nervosa e outras doenças do sistema nervoso como ataques virais, é a apoptose de neurônios na periferia e no sistema nervoso central. A apoptose parece induzir sensibilização e perda do sistema inibitório, causando um processo irreversível (ZIMMERMANN, 2001).

\section{Teoria do controle do gatilho ou do portão}

A teoria do portão proposta por MELZACK e WALL em 1965 (apud MELZACK,1993), muito embora possa ser exposta em termos simples, possui diversificações bastante complexas e por isso vem recebendo muita atenção atualmente, pelo fato de levar em consideração um elemento participante do mecanismo da dor: a emoção. Essa teoria pode ser exposta da seguinte maneira: os milhões de receptores do corpo conservam o cérebro abastecido de informações sobre temperatura e condições dos tecidos e órgãos. Estas informações são moduladas na Lâmina II ou substância gelatinosa. Como já visto, os receptores e o sistema nervoso central comunicam-se por meio de um complexo código neural, que compreende a atividade relativa de fibras grossas e fibras finas. As fibras mais grossas ou $A \beta$ transmitem impulsos como os originados nos receptores do tato; as mais finas, do tipo $C$ e $A \delta$, de transmissão mais lenta, conduzem os impulsos de dor. Esses nervos convergem para a medula espinhal e ali, através de conexões com neurônios WDR, os autores da teoria admitem a existência de um mecanismo semelhante a um portão que usualmente permanece fechado para bloquear a dor mas, às vezes, pode abrir-se para admiti-la (MELZACK, 1993; THURMON et al., 1996).

Quando se arranha a pele suavemente, as fibras grossas conduzem impulsos que são percebidos, porém não traduzem uma sensação desagradável pois a "porta" conserva-se fechada. Se a pele continuar a ser arranhada, cada vez com maior intensidade, mais receptores são estimulados e as fibras grossas sobrecarregadas fazem com que a "porta" se abra e as fibras finas transmitem impulsos dolorosos aos centros nervosos superiores (MELZACK, 1993; THURMON et al., 1996).

Sugere-se ainda que a existência de um estímulo nociceptivo não seja um pré-requisito para geração de dor. A dor seria uma experiência multidi- mensional produzida por padrões característicos ou neuroassinaturas, geneticamente predeterminadas, que podem ser desencadeadas independentemente do estímulo nociceptivo ou modificadas por estímulos nociceptivos ao longo da vida do indivíduo. Esta hipótese poderia explicar o aparecimento da dor fantasma e outras em que a percepção da intensidade da dor é incompatível com a complexidade da patologia (MELZACK, 1993; THURMON et al., 1996).

\section{Resposta sistêmica à dor e injúria}

O sistema nervoso é o principal alvo da informação nociceptiva e fornece o veículo pelo qual o organismo pode reagir contra estímulos. Dor induz respostas reflexas que resultam no aumento do tônus simpático, vasoconstrição, aumento da resistência vascular sistêmica, aumento do débito cardíaco pelo aumento da freqüência cardíaca e do débito cardíaco, aumento do consumo de oxigênio pelo miocárdio, diminuição do tônus gastrointestinal e urinário e aumento do tônus músculo-esquelético (MATHEWS, 2005).

A resposta endócrina compreende aumento da secreção de corticotropina, cortisol, hormônio antidiurético, hormônio do crescimento, AMP cíclico, catecolaminas, renina, angiotensina II, aldosterona, glucagon e interleucina 1 , com concomitante diminuição da secreção de insulina e testosterona. Estas alterações são traduzidas por um estado catabólico caracterizado por hiperglicemia, aumento do catabolismo protéico, lipólise, retenção renal de água e sódio, com aumento da excreção de potássio e diminuição da taxa de filtração glomerular. A estimulação nociceptiva de centros cerebrais leva à hipoventilação e a resposta simpática descrita contribui para aumento da viscosidade sanguínea, aumento do tempo de coagulação, fibrinólise e agregação plaquetária (LAMONT e TRANQUILLI, 2000; MATHEWS, 2005; TEIXEIRA, 2005).

A estimulação nociceptiva do tronco cerebral causa taquipnéia, com tendência à dor, secundária às doenças torácicas e abdominais, resultando em espasmos musculares de reflexo e fadiga involuntária da musculatura e consequente hipoventilação e piora na relação ventilação/perfusão (MATHEWS, 2005).

Estes efeitos constituem a clássica resposta ao estresse e correspondem a uma adaptação desenvolvida para otimizar a sobrevivência no período imediatamente após a injúria. No entanto, a persistência deste quadro clínico pode ser deletério, visto que a resposta neuroendócrina à dor pós traumática ou pós cirúrgica é suficiente para desencadear estado de choque (LAMONT e TRANQUILLI, 2000).

A supressão do eixo adrenal-pituitário da resposta hormonal ao estresse tem sido descrita como o principal objetivo do controle da dor. O reconhecimento 
de marcadores intracelulares do estresse tem redimensionado este objetivo. Estes marcadores são gerados nos neurônios do corno dorsal da medula espinhal e acredita-se que contribuam para mudanças fenotípicas nos neurônios sensoriais periféricos: 1) expressão de genes (c-fos) que codificam proteínas envolvidas na iniciação da excitabilidade neuronal de longa ação, 2) ativação de enzimas (proteína cinase C e óxido nítrico sintase) que produz importante papel na sensibilização central e desenvolvimento de tolerância a opióides, 3) secreção de fator de crescimento neural e citocinas neuropoiéticas que contribuem para sensibilização central e periférica (LAMONT e TRANQUILLI, 2000).

\section{Implicações para o manejo da dor}

Segundo GLEED e LUDDERS (2006) a maioria das síndromes dolorosas são complexas e envolvem mais de um tipo de dor. A primeira estratégia para maximizar o sucesso da terapia analgésica é o conceito de analgesia preemptiva. $O$ tratamento iniciado antes da injúria inibe o processo de sensibilização periférica e central. A segunda estratégia envolve a combinação de fármacos analgésicos e técnicas que promovam efeito sinérgico como analgesia balanceada. Com estas técnicas, pode-se utilizar baixas doses, diminuindo a possibilidade de efeitos colaterais (KUMAZAWA, 1998; LUNA, 2006).

A analgesia preempitva ou analgesia preventiva envolve a administração de analgésicos antes da injúria tecidual, para minimizar a dor pós-operatória e promover um curto período de recuperação ao paciente. $\mathrm{O}$ principal objetivo da analgesia preemptiva é bloquear o Wind-up celular e, com isso, bloquear a sensibilização central, prevenindo a dor ou tornando-a mais fácil de controlar. Apesar do exposto, a técnica não é aceita para indução e manutenção de anestesia isoladamente e não elimina a necessidade de analgésicos no pós-operatório (SHAFFORD et al., 2001; GLEED e LUDDERS, 2006; LUNA, 2006; ROBERTSON, 2006).

A analgesia balanceada ou multimodal utiliza mais de uma modalidade de analgésicos. O processo de nocicepção e dor envolve diversos mecanismos e parece óbvio que um único fármaco não seja capaz de aliviar a dor completamente. Um plano efetivo inclui fármacos de diferentes classes analgésicas, atuando em pontos diferentes dos mecanismos fisiopatológicos que envolvem a dor (ROBERTSON, 2006).

A dor crônica, resultante da persistência de estímulos nociceptivos ou disfunções do sistema nervoso, não é uma versão prolongada da dor aguda. Dor crônica perde a função biológica e caracteriza-se pela sua natureza multidimensional, em que além dos fenômenos neurofisiológicos, os aspectos psicológicos, cognitivos, comportamentais, sociais, familiares e vocacionais também modulam a experiência dolorosa e devem ser combatidos através da terapia multimodal. (LAMONT e TRANQUILLI, 2000).

Os opióides são um grupo de fármacos naturais ou sintéticos amplamente utilizados no manejo de dor pós-operatória e em processos oncológicos. Receptores opióides específicos estão localizados na periferia, medula espinhal e estruturas supra-espinhais, sendo os receptores $\mu(\mathrm{OP} 3)$ e $\kappa(\mathrm{OP} 2)$ os de maior importância clínica reforçando a ação fisiológica das endorfinas e a das vias inibitórias noradrenérgicas e serotoninérgicas. A eficácia analgésica dos opióides pode variar segundo a característica, duração intensidade do estímulo; dosagem e espécie. Os opióides bloqueiam a transmissão periférica e central da via nociceptiva aferente e por isso, tornam-se bastante eficientes no tratamento da dor inflamatória aguda. No entanto, eles não são igualmente eficazes para todo tipo de dor como, por exemplo, a dor neuropática que possui uma resposta pobre ou de curta duração aos opióides (RIBEIRO et al., 2002, BASSANEZI e OLIVEIRA FILHO, 2006). Agentes opióides como tramadol e morfina contribuíram para modulação da resposta neuroendócrina à dor, após a OSH em cães (MASTROCINQUE e FANTONI , 2001).

Os anestésicos locais atuam tanto no bloqueio de canais de sódio, como prevenindo a transmissão do impulso nervoso e a excitação do nociceptor ou inibindo o processo modulatório de nocicepção quando administrado por via central (LAMONT e TRANQUILLI, 2000; BASSANEZI e OLIVEIRA FILHO, 2006).

Os anti-inflamatórios não esteróides (AINE) continuam sendo a principal ferramenta no tratamento da dor crônica. Acredita-se que os efeitos analgésicos destes fármacos deve-se à sua habilidade em inibir a atividade da ciclo-oxigenase e lipo-oxigenase e prevenindo a síntese das prostaglandinas e a sensibilização de nociceptores periféricos. Existem dois tipos principais de COX: a COX-1 e COX-2, presentes na maioria dos tecidos. Existem também relatos da existência de um terceiro tipo de COX (COX-3), presente principalmente no córtex cerebral, que é inibida seletivamente por drogas analgésicas e antipiréticas, como a dipirona e o acetaminofeno. A ação dos AINE é dose /resposta limitada (efeito teto), ou seja, a sua administração em doses superiores às recomendadas não proporciona analgesia suplementar, aumentando a incidência de efeitos colaterais. (LAMONT e TRANQUILLI, 2000; BASSANEZI e OLIVEIRA FILHO, 2006; ROBES, 2006).

Já os glucocorticóides diminuem a expressão do ácido araquidônico e conseqüentemente diminuição de seus metabólitos (prostaglandinas, leucotrienos e tromboxanos), diminuem a expressão de interleucinas e TNF $\alpha$ e parecem estar envolvidos na diminuição da resposta dolorosa em processos autoimunes (LAMONT e TRANQUILLI, 2000). 
Os $\alpha_{2}$-agonistas ligam-se a receptores présinápticos $\alpha$ localizados na fibras aferentes simpáticas, modulando a liberação de norepinefrina, substância $P$, peptídeo relacionado com o gene da calcitonina e outros neurotransmissores envolvidos na transmissão da informação nociceptiva. No SNC os receptores $\alpha_{2}$ encontram-se no tronco cerebral e a ativação de seus núcleos resulta em sedação e anestesia. Também no tronco cerebral, a ação dos agonistas $\alpha_{2}$ ativa uma via inibitória descendente da medula espinhal, diminuindo o tônus simpático. $\mathrm{Na}$ medula espinhal estes receptores estão localizados no corno posterior e sua ativação inibe a transmissão da informação dolorosa, resultando em analgesia (LAMONT e TRANQUILLI, 2000; BASSANEZI e OLIVEIRA FILHO, 2006).

Os antagonistas dos receptores NMDA como a cetamina, previnem o fenômeno de "wind-up" e a conseqüente sensibilização dos neurônios do corno dorsal. Devido seu efeito modulatório da medula espinhal, a cetamina pode ser eficaz no tratamento de dor neuropática que normalmente não responde a opióides (LAMONT e TRANQUILLI, 2000).

Os anestésicos gerais não são analgésicos. Entretanto estes fármacos inibem a percepção da dor induzindo o córtex cerebral à não percepção da informação nociceptiva que está sendo recebida (inconsciência) (ROBERTSON, 2006).

\section{Novos indicadores na terapêutica da dor}

A supressão da resposta clássica do eixo pituitário-adrenal ao estresse, sempre foi reconhecido como o principal objetivo do manejo da dor. O reconhecimento de novos marcadores intracelulares gerados em neurônios do corno dorsal da medula espinhal criou um novo impulso para futuras terapias analgésicas. Estes marcadores são responsáveis pelas alterações fenotípicas nos neurônios sensoriais periféricos: 1) expressão de genes (c-fos) que codificam proteínas envolvidas na iniciação da excitabilidade neuronal de longa duração. 2) ativação de enzimas (proteína cinase $\mathrm{C}$ e NOS) que possuem um importante papel na sensibilização central e desenvolvimento da tolerância por opióides. 3) secreção do fator de crescimento neural e citocinas neuropoiéticas, contribuindo para sensibilização central e periférica (LAMONT e TRANQUILLI, 2000).

\section{CONCLUSÃO}

O conhecimento da patofisiologia da dor ou nocicepção é uma importante ferramenta para o entendimento dos mecanismos desencadeantes dos processos dolorosos, sejam fisiológicos ou principal- mente patológicos. Tais informações são essenciais para a instituição de uma terapia analgésica eficiente, preemptiva e multimodal, pois a síndrome dolorosa pode ser considerada uma doença, gerando alterações na homeostasia orgânica que implicam em perda da qualidade de vida do paciente.

As conseqüências negativas da dor de longe excedem alguma preocupação especial para a utilização de analgésicos. O estresse causado por tal situação deve ser impedido de tomar proporções catastróficas para o indivíduo, ou seja, antes que haja a exaustão das reservas biológicas de energia. Devese ter em mente que não existem efeitos negativos da utilização dos analgésicos, mas sim, relacionados à escolha inadequada ou a dose.

\section{REFERÊNCIAS}

ALMEIDA, T. P.; MAIA, J. Z.; FISCHER, C. D. B.; PINTO, V. M.; PULZ, R. S.; RODRIGUES, P. R. C. Classificação dos processos dolorosos em medicina veterinária. Veterinária em Foco, v. 3, n. 2, p. 107118, 2006.

BASSANEZI, B. S. B.; OLIVEIRA FILHO, A. G. D. E. Analgesia pós-operatória. Revista do Colégio Brasileiro de Cirurgia, v. 33 n. 2, p. 116-122, 2006.

BESSON, J.M. The complexity of physiopharmacologic aspects of pain. Drugs, v. 53, Suppl. 2, p.1-9, 1997.

DREWES, A.M. The physiology of pain. Ugeskrift for Laeger, v.168, n. 20, p. 1941-1943, 2006.

FANTONI, D. T.; MASTROCINQUE, S. Fisiopatologia e Controle da Dor. In: FANTONI, D.T.; CORTOPASSI, S. R. G. Anestesia em Cães e Gatos. São Paulo: Rocca, 2002. p. 323-334.

FORSS, N.; RAIJ, T. T.; SEPPA, M.; HARI, R. Common cortical network for fisrst and second pain. Neuroimage. v. 24, n.1, p. 132-142, 2005.

GARRY, E.M.; JONES, E.; FLEETWOOD-WALKER, S.M. Nociception in vertebrates: key receptor participating in spinal mechanisms of chronic pain in animals. Brain Research Reviews, v. 46, n. 2, p. 216-224, 2004. 
GLEED, R. D.; LUDDERS, J. W. Recent advances in veterinary anesthesia and analgesia: companion animals. International Veterinary Information Service, A1404.0906 2006, disponível em: www. ivis.org, p.1-9 2006.

GOMES, D.; BORGES, D.; PEREZ, D.; DE SOUZA, E.; ANTONIO, F.; CHIERICI, F. Dor, Trabalho de fisiologia - Faculdade de Medicina - USP, 2002.

HELLEBREKERS, L. J. Dor em Animais. São Paulo: Manole, 2002. p. 69-79.

KITAGAWA, J.; KANDA, K.; SUGIURA, M.; TSUBOI, Y.; OGAWA, A.; SHIMIZU, K.; KOYAMA, N.; KAMO, H.; WATANABE, T.; REN, K.; IWATA, K. Effect of chronic inflammation on dorsal horn nociceptive neurons in aged rats. Neurophysiology, v. 93, p. 3594-3604, 2005.

JI, R.R.; WOOLF, C.J. Neuronal plasticity and signal transduction in nociceptive neurons: implications for the initiation and maintenance of pathological pain. Neurobiology of Disease. v. 8, n. 1, p. 1-10, 2001.

JI, R.R.; STRICHARTZ, G. Cell signaling and the genesis of neuropathic pain. Science's STKE, v. 252, re14DOI: 10.1126, 2004

KRAYCHETE, D. C.; GUIMARÃES, A. C. Hiperalgesia visceral e dor abdominal crônica: abordagem diagnóstica e terapêutica Revista Brasileira de Anestesiologia, v. 53, n. 6, p. 833-853, 2003.

KUMAZAWA, T. Primitivism and plasticity of pain implication of polymodal receptors. Neuroscience Research, v. 32, n. 1, p. 9-31. 1998.

LAMONT, L. A.; TRANQUILLI, W. J. Physiology of Pain. The Veterinary Clinics of North America: Small Animal Practice. Philadelphia:Saunders, v.30, n.4, p. 703-728, 2000.

LUNA, S. P. L. Dor, analgesia e bem estar animal. ANAIS - I Congresso Internacional de Conceitos em Bem-estar Animal, p. 16-18, 2006.

MASTROCINQUE, S.; FANTONI T.D. Modulação da resposta neuroendócrina à dor pós-operatória em cães. Clínica Veterinária, n. 31, p. 25-29, 2001.
MATHEWS, K. A. Dor origem e efeito. In: RABELO, R. C.; CROWE JR, D. T. Fundamentos de terapia intensiva veterinária em pequenos animais Condutas no paciente crítico. Rio de Janeiro: L F livros, 2005. p. 519-527.

MELZACK, R. Pain: Past, Present and Future. Canadian Journal of Experimental Psychology, v. 47, n. 4, p. 615-629. 1993.

MELZACK,R.; WALL, E. (1965), apud MELZACK, R. Pain: Past, present and future. Canadian Journal of Experimental Psychology, v. 47, n. 4, p. 615-629. 1993.

MESSLINGER, K. What is a nociceptor? Anaesthesist, v. 46, n. 2, p. 142-53, 1997.

MILLAN, M. J. The induction of pain: an integrative review. Progress in Neurobiology, v. 57, p.1-164, 1999.

MUIR III, W. W.; HUBBELL, J. A. E.; SKARDA, R. T.; BEDNARSKI, R. M. Manual de anesthesia veterinária. 3 ed. Porto Alegre:Artmed, 2001. p. 242-249.

PETERSEN-FELIX, S.; CURATOLO, M. Neuroplasticity - na important factor in acute and chronic pain. Swiss Medical Weekly, v. 132, n. 21-22, p. 273-278. 2002.

PISERA, D. Fisiologia da dor. In: Dor Avaliação e Tratamento em Pequenos Animais. OTERO, P. E. São Paulo:Interbook, 2005. p. 30-74.

PITCHER, G.M.; HENRY, J. L. Nociceptive response to innocuous mechanical stimulation is mediated via myelinated afferents and NK-1 receptor activation in a rat model of neuropathic pain Experimental Neurology, v. 186, n. 2, p. 173-197, 2004.

PLONER, M.; GROSS, J.; TIMMERMANN, L.; SCHNITZLER, A. Pain processing is faster than tactile processing in the human brain. The Journal of Neuroscience, v. 26, n. 42, p. 1079-1082, 2006.

RIBEIRO, S.; SCHMIDT, A. P.; SCHMIDT, S. R. G. O uso de opióides no tratamento da dor crônica não oncológica: o papel da metadona. Revista Brasileira de Anestesiologia, v.52, n.5, p. 644-651, 2002. 
RIEDEL, W.; NEECK, G. Nociception, pain and antinociception: current concepts. Zeitschrift für Rheumatologie, v.60, n. 6, p. 404-415, 2001.

ROBERTSON, S. A. Current concepts in postoperative pain management for companion animal - myths and facts. Proceedings of the 9 World Congress of Veterinary Anaesthesia, p. 41, 2006.

ROBES, R. R. Avaliação do cetorolaco de trometamina e parecoxib para analgesia preemptiva em gatas. Dissertação de mestrado, Pós Graduação em Ciências Veterinárias, Universidade Federal do Paraná, Curitiba, 2006.

RYGH, L.J.; HOLE, K.; TJOLSEN, A. Molecular Mechanisms in Acute anmd Chronic Pain States. Tidsskrift for den Norske Laegeforening, v. 125, n. 17, p. 2374-2377, 2005.

SCHAIBLE, H. G. Pathophysiology of pain. Orthopade. v. 36, n. 1, p. 8-16, 2006.

SCHAIBLE, H.G. Peripheral and central mechanisms of pain generation. Handbook of Experimental Pharmacology, v.177, n.3, p.28, 2007.

SHAFFORD, H. L.; LASCELLES, B. D. X.; HELLYER, P. W. Preemptive analgesia: managing pain before it begins. Veterinary Medicine. v. 194, p. 478-491, 2001.
TEIXEIRA, M. W. Dor em pequenos animais. Revista Conselho Federal de Medicina Veterinária, n. 34, p. 31-40. 2005.

THURMON, J. C.; TRANQUILLI, W. J.; BENSON, G.J. Lumb \& Jone's Veterinary Anesthesia. 3ed. Baltimore:Williams \& Wilkins, 1996. p. 40-57.

TJOLSEN, A.; HOLE, K. Pain regulation and plasticity. Tidsskrift for den Norske Laegeforening, v.113, n. 23, p. 2921-2924, 1993.

TRANQUILLI, W. J. Fisiologia da dor aguda. In: GREENE, S. A. Segredos em anestesia veterinária e manejo da dor. Porto Alegre: Artmed, 2004. p. 399-402.

ZIMMERMANN, M. Pathobiology of neuropathic pain. European Journal of Pharmacology, v. 429, n.1-3, p. 23-37, 2001.

Recebido para publicação:

$29 / 11 / 2006$

Aprovado:

$03 / 03 / 2008$ 